\title{
The Effect of Rebound Therapy on Sitting in Children with Cerebral Palsy
}

\author{
KHADIGA A. MOHAMED, M.Sc.*; HEBATALLA M. KAMAL, Ph.D.*; WALAA ABD EL-NABI, Ph.D.* and \\ AHMED M. KHOLEIF, M.D.** \\ The Department of Physical Therapy for Paediatrics*, Faculty of Physical Therapy, Cairo University and \\ The Department of Orthopedic Surgery**, Faculty of Medicine, Cairo University
}

\begin{abstract}
Background: Sitting is an essential step to achieve upright position and posture background. Cerebral palsy children have poor trunk control and trunk muscles weakness, that contribute to delayed sitting position.
\end{abstract}

Aim of Study: Examine the effect of rebound therapy on sitting in hemiplegic cerebral palsy children.

Material and Methods: Forty children withspastic hemiplegic cerebral palsy, of both sexes, their ages ranged from 6 months to lyear, were randomly assigned into two equal groups. Control groupreceived traditional physical therapy exercises to facilitate sitting, and study groupreceived rebound therapy exercises to facilitate sitting. The gross motor function measure was used to evaluate the sitting in both groups before and after three months of treatment.

Results: The results showed significant difference in some items of GMFMS before and after treatment in both groups (control and study group), while there was nosignificant difference inanother items in both groups.

Conclusion: The obtained results suggested that rebound therapy exercises may be beneficial in improving sitting in children with hemiplegic cerebral palsy.

Key Words: Cerebral palsy - Hemiplegia - Rebound therapy - Sitting.

\section{Introduction}

CEREBRAL Palsy (CP) describes a group of upper motor neuron syndromes secondary to a wide range of genetic and acquired disorders of early brain development. In addition to primary impairments in gross and fine motor function, there may be associated problems with cognition, seizures, vision, swallowing, speech, bowel, bladder, and orthopedic deformities. It is the most prevalent chronic childhood motor disability; affecting 2-3 in1000 school aged children. Cerebral palsy is

Correspondence to: Dr. Khadiga A. Mohamed, The Department of Physical Therapy for Paediatrics, Faculty of Physical Therapy, Cairo University considered non-progressive, but neurological findings may change or progress over time [1].

Motor impairments associated with $\mathrm{CP}$ are often accompanied by disturbances of cognition, behavior, communication, sensation, epilepsy, and perception [2].

There are different kinds of cerebral palsy, depending on the parts of the brain that have been damaged, and each kind is recognized by the way in which the child's postural tone is altered. Spasticity: The muscles are stiff. The child moves in patterns that are not useful and in a limited way. As trying to move, the muscles become stiffer, due to damage in movement areas and pathways of the cortex. Athetosis: There is movement all the timeunwanted movement or movement that is uncontrolled. The muscles may be stiff one moment and floppy the next. In such children the basal ganglia of the brain are damaged. Ataxia: The muscles constantly quiver when the child tries to move. Stiffinghim to overcome this. In these children the cerebellum is damaged. Hypotonia: The muscles are constantly floppy [3].

Hemiplegia is defined as involvement of ipsilateral upper and lower limbs, with the upper limb more severely affected than the lower limb, hand function being most affected. A focal lesion is likely to be the cause of hemiplegia [4]. Hemiplegia refer to weakness or stiffness of just one side of the body, whether the left or right. Most individuals with hemiplegia are adults who have had strokes, but minority acquired their hemiplegia before they were born, around the time of birth, or in the first few years of life. These early onset forms of hemiplegia are described as hemiplegia cerebral palsy. Cerebral palsy is the most common chronic neurodevelopmental disorder and hemiplegic cerebral 
palsy is the most common form of cerebral palsy, affecting up to one per thousand of live births [5]

The ability to control sitting balance gradually emerges in children with Typical Development (TD) during the period from about two to nine months of age, with head control developing first, followed by progressive development of trunk control. In children with neuro-motor disability development of sitting balance is delayed and, depending on the level of disability, children may continue to show constraints on sitting balance throughout their lives with some never gaining independent control of the trunk and head [6] Children with $\mathrm{CP}$ who do not gain independent sitting balance by 4 years of age have poor prognosis for motor skill developmentand increased risk of secondary deficits. Sitting performance in children with $\mathrm{CP}$ included impairments in postural responses due to external perturbations, impairments in anticipatory postural responses during reaching and changes in ground reaction forces during postural adjustments. Impairments such as spasticity, muscle weakness, excessive co-activation of agonist/antagonist muscles, decreased muscle coordination, and decreased response variability contribute to postural deficits in these children [7] Sitting exercises are important for improved postural alignment, development of motor skills, helping the prevention of fixed deformity and facilitation of upper extremity function [8].

Rebound therapy may be of benefit to children with physical disabilities. It can provide an unstable surface, provoke feelings of weightlessness. Rebound therapy provides constant opportunity for sensory integration, visual, and vestibular input. The vestibular sensory system, which responds to changes in head position, body movement and the pull of gravity, is heightened in rebound therapy because of the vertical motions of the body on the trampoline [9]. Rebound therapy is useful for maintenance of general physical function, reduction in abnormal muscle tone, contributing to postural management, improved core and general muscle strength, promotion of healthy bones through weight-bearing activity, increased balance, coordination, proprioception and promotion of good mental health [10]. Therefore, the purpose of this work was to study the effect of rebound therapy on sitting in hemiplegic cerebral palsy children.

\section{Patients and Methods}

Study design:

Pre and postexperimental study.
Forty children with hemiplegic $\mathrm{CP}$ aged from 6 months to 1 year old participated in this study. They were selected from the outpatient clinic of National Institute of Neuro-motor Systemin the period from January 2016 to April 2016. They were assigned randomly into two groups of equal numbers. The control group received traditional physical therapy exercise program to facilitate sitting and the study group received rebound therapy exercise program to facilitate sitting, in addition to the same physical therapy program given to the control group. Treatment program of both groups was conducted for three successive months, three times per week, one hour per session. The study was conducted from January 2016 to April 2017.

A- Inclusion criteria: Their ages ranged from 6 months to 1 year.

- The degree of spasticity ranged from 1 and $1+$ according to Modified Ashworth Scales [11].

- They were categorized on level IV according to Gross Motor Function Classification System (GMFCS).

- They were able to understand and follow simple order.

\section{B- Exclusive criteria:}

- Fixed deformity of both upper and lower limbs.

- Visual or hearing defect.

- Open wounds or infective skin disease.

- Fever $\left(>38^{\circ} \mathrm{C}\right)$, chest infections or unstable cardiac status.

- Seizures.

- Previous history of surgical interference (orthopedic or neurosurgeries).

\section{Instrumentation:}

\section{1- For evaluation:}

- Modified Ashworth Scale.

- Gross Motor Function Classification System (GMFCS): GMFCS was used to select hemiplegic cerebral palsy children.

- Gross Motor Functional measurement (GMFM): For measuring the change in gross motor function (sitting) over time in children with cerebral palsy.

\section{2- For treatment:}

Physical therapy tools of different shapes in the form of: Mats, wedges, and medical balls.

Trampoline consisted of unstable surface mat with $1.22 \mathrm{R}$ diameter, frame section 7.32 Meter- 
height, net, legs, vertical leg support, C-clips (attached to frame) and nuts.

\section{Evaluation procedures:}

\section{A- For selection:}

1- Modified Ashworth scale: It was used to select the children according to the level of spasticity.

2- Gross Motor Function Classification System: Children in this study were categorized on level IV according to Gross Motor Function Classification System (GMFCS). Level IV: Infants have head control but trunk support is required for floor sitting. Infants can roll to supine and may roll to prone.

\section{B- For evaluation:}

- Gross Motor Function Measurement (GMFM): The test is designed to assess motor function or how much of the activity a child can accomplish. It is an evaluative index of gross motor function and changes in function over time, or after therapy, specifically for children with cerebral palsy. The original validation sample included children 5 months to 16 years old. The GMFM is appropriate for children whose motor skills are at or below those of a 5-year-old child without any motor disability [13].

Scoring key:

$0=$ Does not initiate.

$1=$ Initiates.

$2=$ Partially completes.

$3=$ Completes.

Total dimension of sitting $/ 60=* 100=\%)$ [13]

Items of sitting milestone according to GMFMS:

18- Supine, hands grasped by examiner: Pull self to sitting with head control.

19- Sup: Rolls to R side, attains sitting.

20- Sup: Rolls to R side, attains sitting.

21- Sit on mat, supported at thorax by therapist: Lifts head up right maintains 3 seconds.

22- Sit on mat, supported at thorax by therapist: Lifts head up right maintains 10 seconds.

23- Sit on mat, arm(S) propping: Maintain $5 \mathrm{sec}-$ onds.

24- Sit on mat, $\operatorname{arm}(\mathrm{S})$ free: Maintain 3 seconds.

25- Sit on mat with small toys in front: Leans forward, touches toys, re-erect without arms propping.
26- Sit on mat: Touches toy placed 45 behind child's R side, returns to start.

27- Sit on mat: Touches toy placed 45 behind child's R side, returns to start.

28- R side sit: Maintains, arms free, 5 seconds.

29- L side sit: Maintains, arms free, 5 seconds.

30- Sit on mat: Lowers to PR with control.

31- Sit on mat: With feet in front: Attains 4 point over R side.

32- Sit on mat: With feet in front: attains 4 point over L side.

33- Sit on mat: Pivots 90, without arms assisting.

34- Sit on bench: Maintains, arms and feet free, 10 seconds.

35- STD: Attains on small bench.

36- On the floor: Attains sit on small bench.

37- On the floor: Attains sit on large bench [13]

B- Treatment procedures: Control group (A): Children received the traditional physical therapy program to facilitate sitting milestone, that was conducted once a day for one hour per session, 3 times per week for 3 successive months. The program included the following exercises according to Martin and Kessler [14]:

\section{1- From supine to sit:}

- The child was lying down against back support; we encouraged him to come up to sitting position. Our grasp was at his hands and his elbows were maintained straight during the coming up from supine.

- The back support was gradually lowered, so that eventually the child raised his head and trunk from supine to sitting position.

2- Pull from supine lying position to side sit to right side: The appropriate head lifting was facilitated inside lying by providing downward pressure on his/her shoulder, the child pushed up to an elbow, the movement continued as the child pushed up on an extended arm.

3- Pull from supine lying position to side sit to left side: As pervious exercise but on left side.

4- Sitting propped on both arms: The beginning position was sitting, with the child beard his/her weight on extended arms. Various sitting postures could be used, such as abducted long sitting, ring sitting, or tailor sitting. The child must be able to sustain some weight on the arms. Gentle approximation through the shoulders 
into the hands was applied to reinforce the posture. Weight bearing encourages a supporting response from the muscles of the shoulder girdle and the upper extremities to maintain the position.

5- Sitting with one hand weight bearing: The beginning position was sitting, with the child beard his/her weight on extended arms. Various sitting postures could be used, such as abducted long sitting, ring sitting, or tailor sitting. The child must be able to sustain some weight on the arms. Gentle approximation through the shoulders into the hands was applied to reinforce the posture. Weight bearing encourages a supporting response from the muscles of the shoulder girdle and the upper extremities to maintain the position. When bilateral propping was possible, weight shifting in the position could encourage unloading of one extremity for reaching or pointing and could allow for propping on one arm.

6- Sitting without hands support: Progressing from support on one hand to no hand support can be encouraged by having the child shift weight away from the propped hand and then having her attempt to reach with the propped hand.

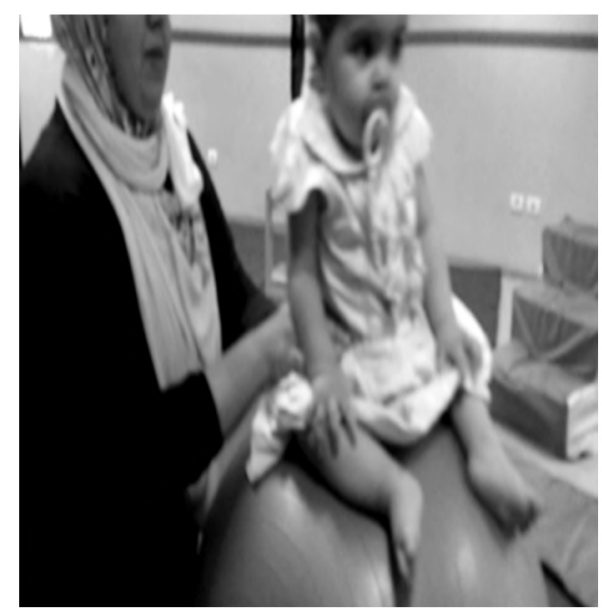

Righting and equilibrium reaction on the ball.

\section{Statistical analysis:}

SPSS for windows, Version 18 (SPSS, Inc., Chicago, IL) was used for statistical analysis Descriptive statistics were used to describe the data in the form of mean and standard deviation. Paired $t$-test was used to compare between Gross Motor Function Measure items pre and post treatment in each group and unpaired $t$-test was used to compare between the control and study groups for GMFS and Gross Motor Function Measure items with alpha level set at 0.05 .
Engaging the child in clapping hands or batting a balloon may also afford opportunities to free the propping hand.

\section{7 - Righting, equilibrium, tilting and protective} reaction on the ball:

Procedure: With infant positioned in sitting, she was pushed laterally, forward or backward to elicit protective response, child extended arm to side, front or behind to prevent self-form falling.

Rebound therapy: Children in the study group received selected program to facilitate sitting on the trampoline that was conducted once a day for one hour, 3 times/week for 3 successive month as the following:

- Pull to sit from supine lying position.

- Pull from supine lying position to side sit to right side.

- Pull from supine lying position to side sit to left side.

- Sitting with arms propped.

- Sitting with hand weight bearing.

- Sitting with arms free.

- Righting and equilibrium reaction on the ball.

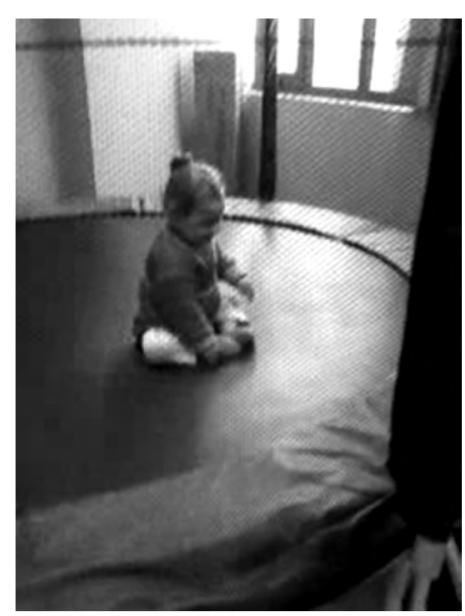

Sitting with arms free.

\section{Results}

The collected data from this study represented the statistical analysis of development of sitting milestone measured by gross motor function measurement. Data were obtained from both groups; physical therapy exercises group and rebound therapy exercises group before and after three months of treatment. Mean ages and standard deviation (mean \pm standard deviation) of physical therapy and rebound therapy group were $(9.8 \pm 1)$ and $(9.95 \pm 1)$ months respectively. There were no 
significant difference between both groups in their ages and their $p$-values was $(0.34,0.73)$ as illustrated in (Table 1).

Table (1): Demographic and general characteristics of the patients for both groups. General characteristics of patients in both groups (A \& B).

\begin{tabular}{lccc}
\hline General & Group A & Group B & Comparison \\
characteristic & Mean \pm SD & Mean \pm SD & $t$-value $p$-value
\end{tabular}

\begin{tabular}{llllll}
\hline Age (month) & $9.8 \pm 1$ & $9.95 \pm 1$ & 0.34 & 0.73 & NS \\
\hline
\end{tabular}

Significance (S) $p \geq 0.05$.

Non Significance (NS) $p \leq 0.05$.

Table (2): Comparisons between pre mean value of GMFS of control and study groups.

\begin{tabular}{lllllll}
\hline & \multicolumn{5}{c}{ Control } & \multicolumn{2}{c}{ Study } & & \\
\cline { 2 - 5 } & Mean & SD & Mean & SD & & $p$-value \\
\hline B18 & 1.70 & 1.12 & 2.30 & 0.80 & -1.93 & $0.06 \mathrm{NS}$ \\
B19 & 0.05 & .22 & 0.20 & 0.41 & -1.43 & $0.15 \mathrm{NS}$ \\
B20 & 0.00 & 0.000 & 0.15 & 0.36 & -1.83 & $0.07 \mathrm{NS}$ \\
B21 & 1.90 & 1.16 & 2.45 & 0.75 & -1.76 & $0.08 \mathrm{NS}$ \\
B22 & 1.40 & 1.23 & 2.00 & 0.91 & -1.74 & $0.08 \mathrm{NS}$ \\
B23 & 0.70 & 1.03 & 1.65 & 2.45 & -1.59 & $0.11 \mathrm{NS}$ \\
B24 & 0.40 & 0.82 & 0.75 & 1.07 & -1.16 & $0.25 \mathrm{NS}$ \\
B25 & 0.40 & 0.82 & 0.55 & 0.99 & -0.51 & $0.06 \mathrm{NS}$ \\
B26 & 0.20 & 0.61 & 0.35 & 0.81 & -0.65 & $0.51 \mathrm{NS}$ \\
B27 & 0.20 & 0.61 & 0.35 & 0.81 & -0.65 & $0.51 \mathrm{NS}$ \\
B28 & 0.00 & 0.00 & 0.30 & 0.73 & -1.83 & $0.07 \mathrm{NS}$ \\
B29 & 0.00 & 0.000 & 0.15 & 0.36 & -1.83 & $0.07 \mathrm{NS}$ \\
B30 & 0.1 & 0.3 & 0.35 & 0.48 & -1.93 & $0.06 \mathrm{NS}$ \\
B31 & 0.05 & 0.22 & 0.20 & 0.41 & -1.43 & $0.15 \mathrm{NS}$ \\
B32 & 0.1 & 0.3 & 0.20 & 0.41 & -0.87 & 0.3 8NS \\
B33 & 0.00 & 0.000 & 0.15 & 0.36 & -1.83 & $0.07 \mathrm{NS}$ \\
B34 & 0.05 & 0.22 & 0.20 & 0.41 & -1.43 & $0.15 \mathrm{NS}$ \\
B35 & 0.00 & 0.00 & 0.10 & 0.30 & -1.45 & $0.15 \mathrm{NS}$ \\
B36 & 0.00 & 0.000 & 0.10 & 0.30 & -1.45 & $0.15 \mathrm{NS}$ \\
B37 & 0.00 & 0.000 & 0.10 & 0.30 & -1.45 & $0.15 \mathrm{NS}$ \\
\hline
\end{tabular}

Table (3): Comparisons between post mean value of GMFS of control and study groups.

\begin{tabular}{lcccccl}
\hline & \multicolumn{2}{c}{ Control } & \multicolumn{2}{c}{ Study } & & \\
& Mean & SD & Mean & SD & & $p$-value \\
\hline B18 & 2.40 & 0.82 & 2.85 & 0.36 & -2.23 & $0.03 \mathrm{~S}$ \\
B19 & 0.10 & 0.44 & 0.75 & 0.85 & 3.02 & $0.004 \mathrm{~S}$ \\
B20 & 0.20 & 0.61 & 0.75 & 0.85 & 2.34 & $0.02 \mathrm{~S}$ \\
B21 & 0.40 & 0.82 & 2.80 & 0.41 & -1.94 & $0.05 \mathrm{NS}$ \\
B22 & 2.35 & 0.81 & 2.75 & 0.55 & -1.82 & $0.07 \mathrm{NS}$ \\
B23 & 1.70 & 1.03 & 2.40 & 0.82 & 2.37 & $0.02 \mathrm{~S}$ \\
B24 & 1.25 & 1.29 & 1.85 & 1.08 & -1.58 & $0.12 \mathrm{NS}$ \\
B25 & 0.85 & 1.26 & 1.35 & 1.04 & -1.36 & $0.18 \mathrm{NS}$ \\
B26 & 0.45 & 0.82 & 0.85 & 0.93 & -1.43 & $0.15 \mathrm{NS}$ \\
B27 & 0.45 & 0.82 & 0.85 & 0.93 & -1.43 & $0.15 \mathrm{NS}$ \\
B28 & 0.15 & 0.36 & 0.50 & 0.68 & 2.008 & $0.05 \mathrm{NS}$ \\
B29 & 0.15 & 0.36 & 0.55 & 0.75 & 2.12 & $0.04 \mathrm{~S}$ \\
B30 & 0.10 & 0.30 & 0.70 & 0.86 & -2.92 & $0.006 \mathrm{~S}$ \\
B31 & 0.05 & 0.22 & 0.45 & 0.68 & -2.47 & $0.018 \mathrm{~S}$ \\
B32 & 0.05 & 0.22 & 0.50 & 0.68 & -2.78 & $0.008 \mathrm{~S}$ \\
B33 & 0.20 & 0.69 & 0.55 & 0.82 & -1.45 & $0.15 \mathrm{NS}$ \\
B34 & 0.15 & 0.48 & 0.65 & 0.87 & -2.23 & $0.03 \mathrm{~S}$ \\
B35 & 0.20 & 0.52 & 0.60 & 0.99 & -1.59 & $0.12 \mathrm{NS}$ \\
B36 & 0.20 & 0.52 & 0.65 & 0.98 & -1.80 & $0.08 \mathrm{NS}$ \\
B37 & 0.20 & 0.52 & 0.65 & 0.98 & -1.80 & $0.08 \mathrm{NS}$ \\
\hline
\end{tabular}

Table (4): Comparison between pre and post mean value of GMFS for sitting milestone of control group.

\begin{tabular}{|c|c|c|c|c|c|c|}
\hline & \multicolumn{2}{|c|}{ Pre } & \multicolumn{2}{|c|}{ Post } & \multirow{2}{*}{$t$-value } & \multirow{2}{*}{$p$-value } \\
\hline & Mean & SD & Mean & SD & & \\
\hline B18 & 1.70 & 1.12 & 2.40 & 0.82 & -4.76 & $0.0001 \mathrm{~S}$ \\
\hline B19 & 0.05 & 0.22 & 0.10 & 0.44 & -1.00 & $0.33 \mathrm{NS}$ \\
\hline B20 & 0.00 & 0.00 & 0.20 & 0.61 & 1.45 & $0.16 \mathrm{NS}$ \\
\hline B21 & 1.90 & 1.16 & 2.40 & 0.82 & -4.35 & $0.000 \mathrm{~S}$ \\
\hline B22 & 1.40 & 1.23 & 2.35 & 0.81 & -5.14 & $0.000 \mathrm{~S}$ \\
\hline B23 & 0.70 & 1.03 & 1.70 & 1.03 & -4.35 & $0.000 \mathrm{~S}$ \\
\hline B24 & 0.40 & 0.82 & 1.25 & 1.29 & -3.65 & $0.002 \mathrm{~S}$ \\
\hline B25 & 0.40 & 0.82 & 0.85 & 1.26 & -2.13 & $0.04 \mathrm{~S}$ \\
\hline B26 & 0.20 & 0.61 & 0.45 & 0.82 & -1.75 & $0.09 \mathrm{NS}$ \\
\hline B27 & 0.20 & 0.61 & 0.45 & 0.82 & -1.75 & $0.09 \mathrm{NS}$ \\
\hline B28 & 0.00 & 0.000 & 0.15 & 0.36 & -1.83 & $0.08 \mathrm{NS}$ \\
\hline B29 & 0.00 & 0.000 & 0.15 & 0.36 & -1.83 & $0.08 \mathrm{NS}$ \\
\hline B30 & 0.1 & 0.3 & 0.10 & 0.30 & 0.0 & $1.0 \mathrm{NS}$ \\
\hline B31 & 0.05 & 0.22 & 0.05 & 0.22 & 0.0 & $1.0 \mathrm{NS}$ \\
\hline B32 & 0.1 & 0.3 & 0.20 & 0.69 & -1.0 & $0.33 \mathrm{NS}$ \\
\hline B33 & 0.00 & 0.000 & 0.20 & 0.69 & -1.28 & $0.21 \mathrm{NS}$ \\
\hline B34 & 0.05 & 0.22 & 0.15 & 0.48 & -0.8 & $0.42 \mathrm{NS}$ \\
\hline B35 & 0.00 & 0.000 & 0.20 & 0.52 & -1.71 & $0.10 \mathrm{NS}$ \\
\hline B36 & 0.00 & 0.000 & 0.20 & 0.52 & -1.71 & $0.10 \mathrm{NS}$ \\
\hline B37 & 0.00 & 0.000 & 0.20 & 0.52 & -1.71 & $0.10 \mathrm{NS}$ \\
\hline
\end{tabular}

Table (5): Comparison between pre and post mean value of GMFS for study group.

\begin{tabular}{|c|c|c|c|c|c|c|}
\hline & \multicolumn{2}{|c|}{ Pre } & \multicolumn{2}{|c|}{ Post } & \multirow{2}{*}{$t$-value } & \multirow{2}{*}{$p$-value } \\
\hline & Mean & SD & Mean & SD & & \\
\hline B18 & 2.30 & 0.80 & 2.85 & 0.36 & -4.06 & $0.001 \mathrm{~S}$ \\
\hline B19 & 0.20 & 0.41 & 0.75 & 0.85 & -2.77 & $0.012 \mathrm{~S}$ \\
\hline B20 & 0.15 & 0.36 & 0.75 & 0.85 & -3.26 & $0.004 \mathrm{~S}$ \\
\hline B21 & 2.45 & 0.75 & 2.8 & 0.41 & -2.33 & $0.031 \mathrm{~S}$ \\
\hline B22 & 2.00 & 0.91 & 2.75 & 0.55 & -3.94 & $0.001 \mathrm{~S}$ \\
\hline B23 & 1.65 & 2.45 & 2.40 & 0.82 & -1.35 & $0.19 \mathrm{NS}$ \\
\hline B24 & 0.75 & 1.07 & 1.85 & 1.08 & -4.81 & $0.000 \mathrm{~S}$ \\
\hline B25 & 0.55 & 0.99 & 1.35 & 1.04 & -4.000 & $0.001 \mathrm{~S}$ \\
\hline B26 & 0.35 & 0.81 & 0.85 & 0.93 & -2.93 & $0.008 \mathrm{~S}$ \\
\hline B27 & 0.35 & 0.81 & 0.85 & 0.93 & -2.93 & $0.008 \mathrm{~S}$ \\
\hline B28 & 0.30 & 0.73 & 0.50 & 0.68 & -1.07 & $0.29 \mathrm{NS}$ \\
\hline B29 & 0.15 & 0.36 & 0.55 & 0.75 & -2.37 & $0.028 \mathrm{~S}$ \\
\hline B30 & 0.35 & 0.48 & 0.70 & 0.86 & -1.78 & $0.09 \mathrm{NS}$ \\
\hline B31 & 0.20 & 0.41 & 0.45 & 0.68 & -1.56 & $0.13 \mathrm{NS}$ \\
\hline B32 & 0.20 & 0.41 & 0.55 & 0.82 & -1.78 & $0.09 \mathrm{NS}$ \\
\hline B33 & 0.15 & 0.36 & 0.55 & 0.82 & -2.17 & $0.04 \mathrm{~S}$ \\
\hline B34 & 0.20 & 0.41 & 0.65 & 0.87 & -2.26 & $0.03 \mathrm{~S}$ \\
\hline B35 & 0.10 & 0.30 & 0.60 & 0.99 & -2.23 & $0.03 \mathrm{~S}$ \\
\hline B36 & 0.10 & 0.30 & 0.65 & 0.98 & -2.46 & $0.02 \mathrm{~S}$ \\
\hline B37 & 0.10 & 0.30 & 0.65 & 0.98 & -2.46 & $0.02 \mathrm{~S}$ \\
\hline
\end{tabular}

\section{Discussion}

The present study was conducted to determine the effect of rebound therapy on sitting in hemiplegic cerebral children. For this purpose, forty spastic hemiplegic cerebral palsied children were chosen with ages ranged from 6 months to 1years. They were divided equally into two groups' control (A) and study (B) group. The children in control 
group (A) received traditional physical therapy exercise to facilitate sitting whereas study group (B) received rebound therapy exercise to facilitate sitting.

Choosing the age of the children was in agreement with Tecklin [15] who reported that child begins at approximately 6 to 7 to months of age, to exhibit his first abilities for sitting without the external support of either being held or sitting with a backrest and have good sitting at 10 month. Choosing the age of the children representing the study sample ranged from 6 month or 7 month to 2 years. This selection of age group is confirmed by the findings of Esposito and Venuti [16] who stated that typically developing infants are able to sit without external support, on average, at about seven to eight months. This movement requires integration among the vestibular centers and the muscles that control the trunk and hips. Although the sitting posture is usually achieved during the second half of the first year of life, its emergence is a continuous process.

Selecting GMFM for evaluating sitting milestone is supported by the opinion of Pountney [17] who stated that the gross motor function measure a commonly used measurement tool for children with cerebral palsy. The GMFM-66 is quicker to administer due to its fewer items and allows for interval scale measures rather than ordinal scale measure, thereby enabling a higher level of statistical analysis. Each item is clearly described and standardized performance outcome descriptors assist with scoring. An extensive manual supports the assessor. The reliability and validity is high to good.

The pre-treatment data of GMFMS between two groups (control group and study group) revealed no significant difference indicating homogeneity between both groups before starting the study and reflecting the validity of sample collection and random classification of children between both groups.

The result of the present study showed that there was no significance difference between pre and post-treatment means values of the control group in the following items B19, B20, B26, B27, B28, B29, B30, B31, B32, B33, B34, B35, B36 and $B 37$, while there is significance difference between pre and post treatment means values of the control group in the following items B $18, \mathrm{~B} 21$, B22, B23, B24 and B25. This mean that the tradition physical exercises improved sitting milestone. coming in agreement with Jones and Gray [18] who stated that sitting exercises effected on tone or decrease abnormal influence on the body, maintain skeletal alignment, prevent accommodate or correct skeletal deformity, provide stable base of support to promote function, promote increased tolerance of desired position, promote comfort and relaxation, facilitate normal movement patterns or control abnormal movement patterns, decrease fatigue, enhance autonomic nervous system function (cardiac, digestive and respiratory function) and facilitate maximum function with minimum pathology.

The result of the present study showed that there was no significance difference between pre and post treatment means values of the study group in the following items B28, B30, B31, and B32 while there is significance differences between pre and post-treatment means values of the study group in the following items B18, B19, B20, B21, B22, B23, B24, B25, B26, B27, B29, B33, B34, B35, B36, B37. The significance differences in the previous items were supported by the finding of Rennie [19] who concluded that rebound therapy exercises are effective programs for improving sitting milestone in children with hemiplegic cerebral palsy because rebound therapy exercises improve balance, improve posture, improve weight bearing and improve exercise tolerance.

As reported by Hahn et al., [20] concluded that during trampoline training, the participants were forced to continuously respond to changes in gravity, and this provides deep proprioception as well as other sensory inputs. In addition, performance improvements in sitting tasks may be the result of alterations in the complex sensory motor stimulation due to participants' efforts to adapt to the trampoline's unstable surface and maintain balance.

\section{Conclusion:}

Based on our findings, both rebound and traditional physicaltherapy exercises may be useful for children with hemiplegic cerebral palsy to improve sitting. Rebound therapy exercises are an amazing form of exercises for children with hemiplegic cerebral palsy because, it has a unique properties a similar service to that of hydrotherapy and therapeutic horse riding in providing benefits such as altering muscle tone, relaxation, stimulation of balance reactions, postural mechanisms and the facilitation of movement. Rebound therapy provides an extra intervention which can provide children with a feeling of freedom, giving important independent movement time for those with postural management programs and an enjoyable method of exercise, whilst still providing therapeutic effects. 


\section{Acknowledgements:}

The authors would like to express appreciation to all children and their parents who participated in this study and to colleagues at Pediatric Department in National Institute of Neuro-motor System, Giza, Egypt.

\section{References}

1- CAMPBELL S., PALISANO R. and ORLIN M.: Physical Therapy for Children, 4 th ed, 2012.

2- SINGER H., KOSSOFF E., HARTMAN A. and CRAWFORD T.: Treatment of Pediatric Neurologic Disorders, 2005.

3- HINCHCLIFFE A.: Children with cerebral palsy: A manual for therapists, parents and community workers ${ }^{\text {nd }} \mathrm{ed}$, 2007.

4- BIALIK G. and GIVON U.: Cerebral palsy: Classification and etiology, 43 (2): 77-80, 2009.

5- JENNIFER B., TERESA O. and ROBERT G.: Supporting Young adult with hemiplegia: Services and cost, health and social care in community Journal, 9 (1): 51-9, 2001.

6- BUTLER P., SAAVEDRA S., SOFRANAC M., JARVIS S.E. and WOOLLACOTT M.H.: Refinement, Reliability and Validity of the Segmental Assessment of Trunk Control (SATCo), 2010.

7- SAAVEDRA S. and WOOLLACOTT M.: Segmental contributions to trunk control in children with moderateto-severe cerebral palsy, 96 (6): 1088-97, 2015.

8- WESTCOTT S.L. and GOULET C.G.: Neuromuscular system: Structures, functions, diagnosis, and evaluation.
In SK Effgen (Ed) Meeting the Physical Therapy Needs of Children. Philadelphia: FA Davis Company, 2005.

9- GRAHAM A.: The Effect of Rebound Therapy on Muscle Tone, 2006.

10- DAWSON I.: Rebound Therapy in Norfolk April, 2013.

11- BOHANNON R. and SMITH M.: Modified Ashworth Scale Instructions, 1987.

12- BOHANNON R. and SMITH M.: Interrater reliability of a modified Ashworth scale of muscle spasticity; Physical Therapy, 67 (2): 206, 1987.

13- KEITH A.: Gross Motor Function Measure (GMFM) Score Sheet (GMFM-88 and GMFM-66 scoring) Version 1.0, 2002.

14- KESSLER S. and MARTIN M.: Neurologic Interventions for Physical Therapy, ${ }^{\text {rd }}$ ed: 85-8, 2015.

15- TECKLIN J.: Pediatric physical therapy, 5 th ed, 2015.

16- ESPOSITO G. and VENUTI P.: Symmetry in Infancy: Analysis of Motor Development in Autism Spectrum Disorders, 2009.

17- POUNTNEY T.: Physiotherapy for children, 2007.

18- JONES M. and GRAY S.: Assistive technology: Positioning and mobility. In SK Effgen (Ed) Meeting the Physical Therapy Needs of Children, 2005.

19- RENNIE J.: Learning Disability: Physical Therapy Treatment and Management, A Collaborative Appoach 2 edition, 2007.

20- HAHN J., SHIN S. and LEE W.: The effect of modified trampoline training on balance, gait, and falls efficacy of stroke patients, 2015.

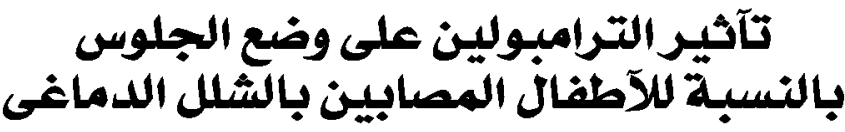

الهدف من الدراسة: لدراسة تآثير الترامبولين على وضع الجلوس فى الآطفال المصابين الشلل الدماغى نصف.

الطريقة: تم إختيار آربعون طفلا من آطفال الثلل المصابين بالثلل الدماغى من الجنسين تتراوح آعمارهم من ستة آثهر إلى سنة إنها

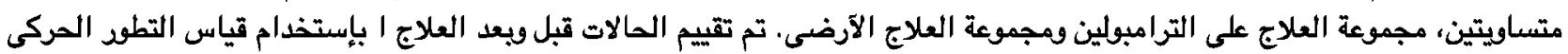

الوظيفى وقد آجريت التمرينات العلاجية لمدة سـاعة بواقع ثلاث جلعات آمسبوعية وتم تقعيههم عشعوائيا إلى مجموعتين، لمدة ثلاثة شهود متواصلة.

بناء على نتائج هذا البحث يمكن إستتاج ما يلى : آظهرت نتائج هذا البحث وجود فروق ذات دلالة إحصائية عالية لمجموعتين عند مقارنة

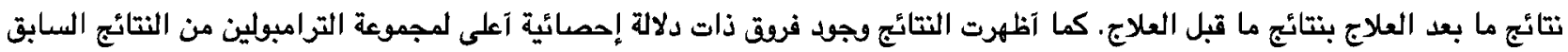

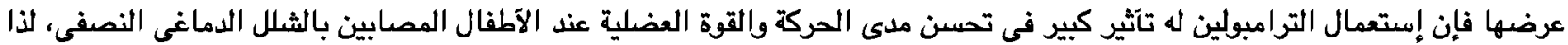

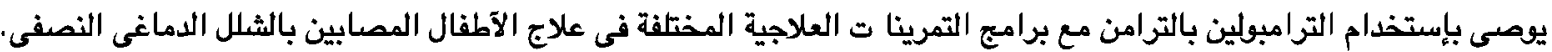

